\title{
Effects of Antrodia camphorata extracts on anti-oxidation, anti-mutagenesis and protection of DNA against hydroxyl radical damage
}

Yu-Lin Hsieh', Szu-Pei Wu' ${ }^{1}$, Li-Wen Fang ${ }^{1}$ and Tzann-Shun Hwang ${ }^{3 *}$

\begin{abstract}
Background: Antrodia camphorata is a geographically special fungus and is one of the precious traditional medicines of Taiwan. A lot of reports have addressed its antioxidant activities and anticancer activities. In order to understand whether these protection effects were resulted from its ability of preventing DNA against hydroxyl radical damage, the A. camphorata extract was used to examine its antioxidant, antimutagenic and DNA-protective activities.

Methods: A. camphorata extract was prepared by extracting the lyophilized powder of A. camphorata mycelium with distilled water. The antioxidative activity of this A. camphorata extract was then evaluated by 2,2-diphenyl-1-picrylhydrozyl $(\mathrm{DPPH})$ radical-scavenging assay, and the antimutagenic activities of the extract against direct mutagen 4-nitroquinoline $\mathrm{N}$-oxide (4NQNO) and indirect mutagen benzo[a]pyrene (B[a]P) were evaluated by Ames test. The effects of the $A$. camphorata extract in terms of DNA protection against hydroxyl radical damage were also investigated.

Results: It was found that the higher the concentration of $A$. camphorata extracts, the higher the DPPH radicalscavenging effect. A. camphorata extract at concentrations between 0.625 and $10 \mathrm{mg} / \mathrm{ml}$ was found to be neither toxic nor mutagenic. However, the higher A. camphorata concentration $(10 \mathrm{mg} / \mathrm{ml})$ used in the test showed higher inhibitory effects on $4 \mathrm{NQNO}$ in a dose-dependent manner. The A. camphorata extract also showed reducing and scavenging activities against superoxide anion radical and also exhibited protective effects on DNA against hydroxyl radical-induced damage.
\end{abstract}

Conclusions: Results suggested that A. camphorata is a non-toxic and novel material with antioxidant, antimutagenic and DNA-protective activities and could be developed into health foods.

Keywords: Antrodia camphorata, Submerged cultivation, Ames test, DNA damage, Antioxidant activity

\section{Background}

Antrodia camphorata (also called Chang-Chih or NiuChang-Ku) is a member of the Polyporaceae (Aphyllophorales) family and hosts in brown heart rot of the endemic evergreen Cinnamomum kanehirai Hay (Lauraceae) in Taiwan [1]. The fruit body of A. camphorata is a wellknown and expensive medicinal material in Taiwan. Traditionally, it is used as an antidote, anti-cancer, anti-itching and hepato-protective medicine. It has a mild camphor

\footnotetext{
* Correspondence: hzx@faculty.pccu.edu.tw

${ }^{3}$ Graduate Institute of Biotechnology, Chinese Culture University, No. 55, Hwa-Kan Rd, Yang-Ming-Shan, Taipei, Taiwan

Full list of author information is available at the end of the article
}

odor like that of its host tree, and the taste of it is very bitter. Currently, there is a shortage of the natural harvested fruit body of $A$. camphorata because its natural host, $C$. kanehirai Hay, is one of the endangered species in Taiwan.

Due to the rareness and growing slowly in natural environments, the fruit bodies of A. camphorata were expensive and difficult to procure; however, a breakthrough occurred in 1998 when a method of submerged culture for growing A. camphorata was established. Since the mycelium of $A$. camphorata was easy to obtain by submerged cultivation, many pharmacological effects of crude extracts of $A$. camphorata in different models of in vivo and in vitro studies were subsequently 
reported. These pharmacological effects were reviewed by Geethangili and Tzeng in 2009 [2] and classified into nine functional categories, including (1) Anti-cancer activities: Both the fruiting bodies and mycelium of $A$. camphorata was reported to have potent antiproliferative activities against various cancers both in vitro and in vivo. (2) Anti-inflammatory and immunomodulatory effects. (3) Anti-hepatitis B virus replication: A. camphorata extracts was reported to have antihepatitis B virus activity in vivo in a dose-dependent manner without cytotoxicity. (4) Antioxidant activities: Accumulating data showed that A. camphorata could be a potent direct free radical scavenger. (5) Hepatoprotective activity: $A$. camphorata was showed to have protective activity against liver hepatitis and fatty liver induced by acute hepatotoxicity of alcohol and also showed to have potential in treating liver diseases. (6) Prevention of liver fibrosis: The filtrate of fermented $A$. camphorata was found to have preventive and curative properties against rat liver fibrosis induced by $\mathrm{CCl}_{4}$-treatment. (7) Neuro-protective effects: Extracts from A. camphorata specimens grown via submerged cultivation were reported to prevent serum-deprived PC-12 cell apoptosis through a PKA-dependent pathway and by suppression of JNK and p38 activities. (8) Anti-hypertensive effects: Methanol extracts of $A$. camphorata showed potent antihypertensive effects in spontaneously hypertensive rats. (9) Vasorelaxation effects: The extracts of submerged cultural mycelium were reported to have vasorelaxation effects in a concentration-dependent manner.

At present, A. camphorata is mainly prepared via the submerged cultivation and used in the formulation of nutraceuticals and functional foods. It is of great interest to examine more functional properties of water extracts of A. camphorata. Few reports thus far, however, have been concerned with studies of the biological and chemical effects of $A$. camphorata extracts at the level of DNA function. Accordingly, the aim of this study was to elucidate the biological and chemical properties of $A$. camphorata extracts, including any effects such as mutagenic activity, anti-mutagenic activity against mutagens, and the protective effect of DNA from hydroxyl radical damage. The antioxidant activity and scavenging effects on radicals were also investigated in this study to compare with other reports.

\section{Methods}

\section{Antrodia camphorata and its composition analyses}

A. camphorata mycelium used in this study was a gift from Prof. Szu-Chuan Shen (National Taiwan Normal University, Taipei), which was produced by Simpson Biotech Co. Ltd. Water content and ash content of A. camphorata were determined according to the standard procedure by using the dried powder of Antrodia camphorata specimens grown by submerged cultivation. The total protein was determined by the Kjeldahl method, as described previously [3].

\section{Preparation of $A$. camphorata extract (ACE)}

Dried A. camphorata mycelium from submerged cultivation was grounded into powder. The A. camphorata extract (ACE) was prepared by water extraction. Two hundred milliliter of distilled water was added into $10 \mathrm{~g}$ of grounded powder, mixed well and stirred at $4{ }^{\circ} \mathrm{C}$ for $24 \mathrm{~h}$. After centrifugation, the clear supernatant was collected, concentrated 10 times by rotary vapor machine, and lyophilized into dry powder by a lyophilyzer. The resultant dry powder was ACE and was stored at $-20{ }^{\circ} \mathrm{C}$ for use in the following experiments.

\section{Evaluation of total phenolic compounds}

The total phenoic content was determined by the following procedure and expressed in terms of milligrams of gallic acid equivalent per gram of aqueous extract [4]. The dried powder of ACE was dissolved in distilled water with a proper concentration. One hundred microlitre of ACE solution was added into $2.0 \mathrm{ml}$ of $2 \% \mathrm{Na}_{2} \mathrm{CO}_{3}$, mixed well and held for $2 \mathrm{~min}$. Folin-ciocalteu's reagent (50\%) was then added into samples, mixed well and held for $30 \mathrm{~min}$. The reacted samples were analyzed by spectrophotometer at $750 \mathrm{~nm}$ to determine the total phenolic compounds.

\section{Scavenging effect on 1,1-Diphenyl-2-picrylhydrazyl radicals}

Scavenging ability on 1,1-Diphenyl-2-picrylhydrazyl $(\mathrm{DPPH})$ radicals was measured by the method described previously [5]. Each water solution of ACE $(0.5-10 \mathrm{mg} /$ $\mathrm{ml}$ ) was mixed with $1 \mathrm{ml}$ of a methanolic solution containing DPPH (Sigma) radicals, resulting in a final concentration of $0.2 \mathrm{mM}$ 1,1-diphenyl-2-picrylhydrazyl (DPPH). The mixture was shaken vigorously and left to stand for $30 \mathrm{~min}$ in the dark, and the absorbance was then measured at $517 \mathrm{~nm}$. Antioxidant butylated hydroxytoluene (BHT) was used as the positive control. The scavenging activity (\%) was defined as the percentage of the reduced absorbance caused by treating DPPH mixture with samples. The absorbance caused by DPPH mixture with water was used as the $100 \%$ control.

$$
\text { Scavenging activity }(\%)=\frac{1-\mathrm{A}_{\text {sample }}}{\mathrm{A}_{\mathrm{H} 2 \mathrm{O}}} \times 100 \%
$$

where $\mathrm{A}_{\text {sample }}$ is the absorbance caused by treating DPPH mixture with samples and $\mathrm{A}_{\mathrm{H} 2 \mathrm{O}}$ is the absorbance by treating DPPH mixture with water. 


\section{Toxicity test}

Salmonella typhimurium TA98 was obtained from the Bioresource Correction and Research Center (BCRC), FIRDI, Hsinchu, Taiwan. The strain was checked by examining its four genotypes according to the method described by Maron and Ames [6], including the histidine requirement in a biotin control plate and a biotin plate with histidine, rfa mutation test, uvr mutation test and R-factor confirmation.

If a sample has toxicity effects on S. typhimurium TA98 in an anti-mutagenic test, it will decrease the number of the testing bacteria and cause a wrong judgment for the data. In order to eliminate such potential error, a toxicity test of ACE was conducted. $0.1 \mathrm{ml}$ of ACE was mixed with $0.5 \mathrm{ml}$ of $0.2 \mathrm{M}$ phosphate buffer (pH7.4) or S9 mixture, then $0.1 \mathrm{ml}$ of activated S. typhimurium TA98 was added and incubated at $37{ }^{\circ} \mathrm{C}$ for $20 \mathrm{~min}$. A $1 \mathrm{ml}$ sample of the bacteria solution was aliquoted on to a plate, nutrient agar was added and the combination was mixed well. The colony formation units were counted after incubation at $37{ }^{\circ} \mathrm{C}$ for $48 \mathrm{~h}$. Distilled water was used as control instead of sample. Colony count was monitored to check whether the colony number was reduced obviously; if yes, the concentration of ACE was further reduced until no toxicity was observed.

\section{Mutagenesis analysis}

Mutagenesis analysis needs to be performed in addition of toxicity testing to eliminate possible errors due to a sample's mutagenic effect, because if a sample has the ability to cause mutations, it will influence the number of revertants and result in an error in judgment. $0.1 \mathrm{ml}$ of ACE was mixed with $0.5 \mathrm{ml}$ of $0.2 \mathrm{M}$ phosphate buffer (pH7.4) or S9 mixture, then $0.1 \mathrm{ml}$ of activated $S$. typhimurium TA98 was added and incubated at $37{ }^{\circ} \mathrm{C}$ for $20 \mathrm{~min}$. Then $2 \mathrm{ml}$ of molten top agar (about $45^{\circ} \mathrm{C}$ ) was added into the tube, mixed well and then poured into a minimal glucose agar plate. Colonies in the plate were counted for the number of $\mathrm{His}^{+}$revertants after incubation at $37{ }^{\circ} \mathrm{C}$ for $48 \mathrm{~h}$. Control was designed by using distilled water instead of sample. Each experiment was repeated three times. If the colony count of sampleinduced revertants is higher than that of the spontaneously occurring revertants, it would suggest that the sample possesses the ability to cause mutagenesis.

\section{Antimutagenic test}

Mutagen 4-nitroquinoline N-oxide (4-NQNO) is a direct mutagen, meaning that it has the ability to cause mutation directly and need not be activated by liver enzyme $\mathrm{S} 9$. Mutagen benzo[a]pyrene $(\mathrm{B}[\mathrm{a}] \mathrm{P})$ is an indirect mutagen, meaning that it requires conversion and activation by the liver enzyme mix $S 9$ to generate the ability of mutation. Mutagen 4-NQNO and $\mathrm{B}[\mathrm{a}] \mathrm{P}$ were prepared in DMSO solution with a concentration of 10 and $50 \mu \mathrm{g} / \mathrm{ml}$, respectively. The test of antimutagenic ability was performed according to the method described by Maron and Ames [4]. ACE solution was mixed with $0.1 \mathrm{ml}$ mutagen (either 4-NQNO or $\mathrm{B}[\mathrm{a}] \mathrm{P}$ ), and $0.5 \mathrm{ml}$ of $0.2 \mathrm{M}$ phosphate buffer ( $\mathrm{pH} 7.4$ ) was added with or without S9 mix. One milliliter of the activated S. typhimurium TA98 was then aliquoted into each of the sample tubes. After incubating at $37{ }^{\circ} \mathrm{C}$ for $20 \mathrm{~min}, 2 \mathrm{ml}$ of molten top agar (about $45^{\circ} \mathrm{C}$ ) was added into each tube, mixed well and then poured into a minimal glucose agar plate. Colonies in the plate were counted for the number of $\mathrm{His}^{+}$revertants after incubation at $37^{\circ} \mathrm{C}$ for $48 \mathrm{~h}$.

\section{Protection effect analysis of DNA damage}

Fenton reaction can generate hydroxyl radicals [7]. The radicals would attack the deoxyribose elements of DNA molecules, degrade the molecules by the release of purine and pyrimidine bases, and produce mutagenic sites $[8,9]$. By assaying the retention of intact DNA molecules, the protection effect of ACE on DNA damage was evaluated.

Each $45 \mu \mathrm{l}$ aliquot of a reaction mixture, which was a blend of ACE (0-200 $\mu$ g total solids $/ \mathrm{ml}), 5 \mu \mathrm{l}$ of calf thymus DNA solution (25.0 $\mathrm{A}_{260} \mathrm{unit} / \mathrm{ml}$ ) (Amersham Biosciences, Piscataway, NJ, USA), $0.9 \mu \mathrm{l}$ of $3.6 \mathrm{mM} \mathrm{FeSO}_{4}$, and $3.6 \mu \mathrm{l}$ of $24 \mathrm{mM}$ hydrogen peroxide, was incubated at room temperature for $15 \mathrm{~min}$. After incubation, $10 \mu \mathrm{l}$ of $1 \mathrm{mM}$ EDTA was added to stop the reaction. The blank was the calf thymus DNA solution. The control was the reaction mixture without ACE. Each $10 \mu \mathrm{l}$ aliquot of the reaction mixture was applied on $1 \%$ agarose gel containing $0.1 \%$ ethidium bromide. The electrophoresis was conducted in TBE buffer $(10 \mathrm{mM}$ Tris-boric acid-EDTA, pH 7.4) for $8 \mathrm{~min}$. The gel was then visualized under UV illumination.

\section{Results and discussion}

\section{Composition of submerged cultured $A$. camphorata}

The composition analysis showed that the water content of the dry powder of the submerged cultured A. camphorata was $17.55 \%$ (Table 1 ). In previous studies, the water content was measured to be $68 \%$ in the fresh fruit

Table 1 The composition of dried powder of Antrodia camphorata

\begin{tabular}{lllll}
\hline Content $^{\mathrm{a}}$ & \multicolumn{3}{l}{} \\
\hline Components & $\begin{array}{l}\text { Moisture } \\
(\%)^{\mathrm{a}}\end{array}$ & $\begin{array}{l}\text { Ash } \\
(\%)^{\mathrm{a}}\end{array}$ & $\begin{array}{l}\text { Crude } \\
\text { protein } \\
(\%)^{\mathrm{a}}\end{array}$ & $\begin{array}{l}\text { Total phenolic } \\
\text { contents } \\
(\mathrm{mg} / \mathrm{g} \text { extract) }\end{array}$ \\
\hline $\begin{array}{l}\text { A. } \\
\text { camphorata }\end{array}$ & $\begin{array}{l}17.55 \pm \\
0.83\end{array}$ & $\begin{array}{l}8.63 \pm \\
0.33\end{array}$ & $\begin{array}{l}25.39 \pm \\
2.11\end{array}$ & $20.00 \pm 0.79$ \\
\hline
\end{tabular}

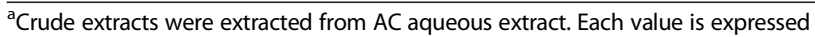
as mean $\pm \mathrm{SD}(n=3)$ Moisture value presented was based on air-dried weight, while the other values presented were based on dry weight 
body of 1 year-old A. camphorata and $7.33 \%$ in the dried fruit body of $A$. camphorata [10]. The higher water content in the submerged cultured $A$. camphorata was possibly caused by their higher sugar content, which made it easy to absorb moisture from the humid air. The ash content of the dry powder of submerged cultured A. camphorata was measured to be $8.63 \%$. This result agreed with the content of general mushrooms supposed to have ash contents between 5 and $16 \%$, which is mainly composed of phosphorus, potassium and other inorganic salt.

The protein content of dry powder of submerged cultured A. camphorata was measured to be $25.39 \%$ (Table 1). The protein content of the A. camphorata mycelium and fruit body was measured to be 23.84 and $6.6 \%$, respectively, in previous studies [10]. This higher protein content should be resulted from the thorough utilization of the nitrogen source in the submerged cultivation.

\section{Total phenolics content and antioxidant activity of $A$.} camphorata extract

It has been reported that phenolic compounds possess antioxidant effects that can be used to clean up the active oxygen and free radicals which can prevent the oxidation of phospholipids in cell membranes and lipids in blood, and that these antioxidant effects can thereby decrease the risk of medical problems due to heart disease or arterial damage, such as strokes. In addition, phenolic compounds have been shown to exhibit anti-mutagenic activity $[11,12]$. Analysis showed that the total phenolic content of ACE was estimated to be $20.00 \mathrm{mg} / \mathrm{g}$ (Table 1). This implied that the antioxidant activity of ACE should be related with the high content of phenolic compounds.

Antioxidant agents for inhibiting the lipid oxidation include providing hydrogen to scavenge peroxide radicals, and DPPH is a stable free radical which could accept electrons or hydrogen free radicals to form a stable molecule [13]; therefore, DPPH is a good chemical to generate free radicals and can be used for measuring the antioxidant activity of materials. In the investigation of scavenging ability for DPPH free radicals, results showed that ACE had significant scavenging ability. The scavenging ability was estimated to be $46.53 \%$ when the concentration of ACE was $2.5 \mathrm{mg} / \mathrm{ml}$, and the scavenging ability was proportional to the concentration of ACE. The positive control BHT also showed a scavenging ability of $92.23 \%$ in the concentration of $0.625 \mathrm{mg} /$ $\mathrm{ml}$ (Fig. 1). The antioxidant properties of A. camphorata were first described by Song et al. in 2002 [14]. It was found DMF and water-extracted ACE showed marked activity in free radical scavengeing and showed that the antioxidant ability of A. camphorata is proportional to the total phenolic content [14]; therefore, it is suggested that the scavenging ability of ACE against DPPH radicals should be contributed from the high content of total phenolics. The antioxidant properties of methanolic extracts from A. camphorata were also reported $[15,16]$. All of studies showed similar results in antioxidant ability, which demonstrated its significant antioxidant activity from the concentration of $\mathrm{mg} / \mathrm{ml}$ level. Our results

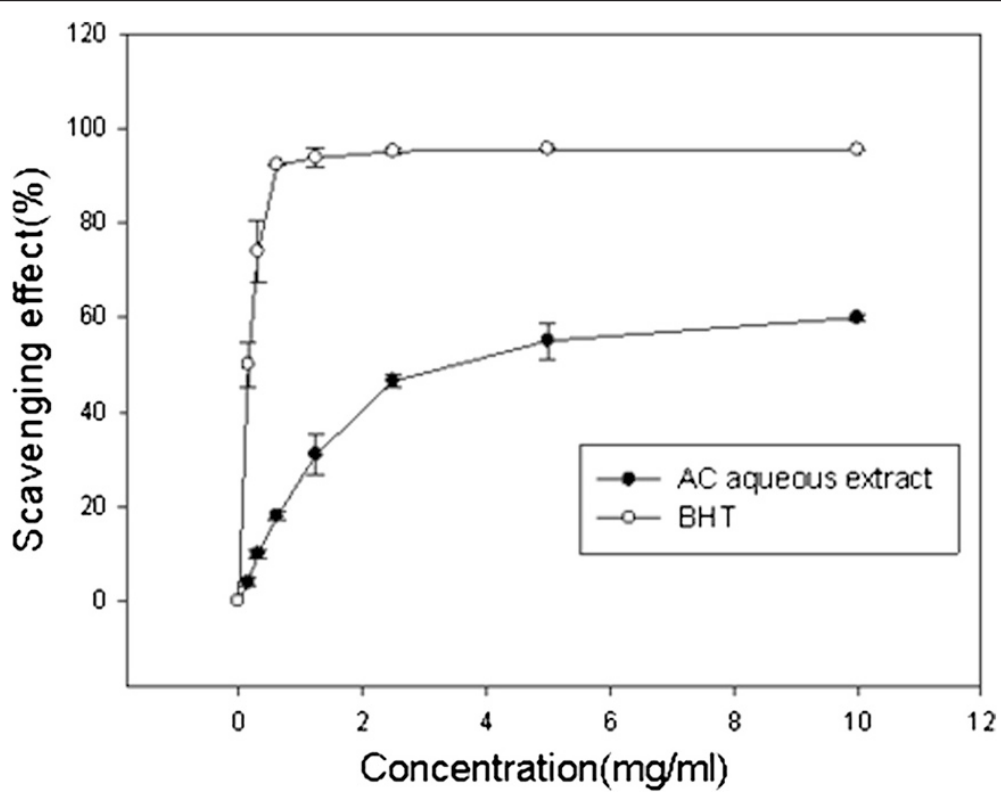

Fig. 1 The scavenging effects of Anthrodia camphorata extract against hydroxyl radicals. Data are expressed as mean \pm SD $(n=3)$. The scavenging effect $(\%)=[1$-(the absorbance of samples at wavelength $517 \mathrm{~nm} /$ the absorbance of control (without sample) at wavelength $517 \mathrm{~nm}$ ) $] \times 100 \%$ 
agreed with the study reported by Song et al. since they also prepared ACE by water extraction; however, lower antioxidant activity and total phenolics content were observed, it should caused by preparing extract at $4{ }^{\circ} \mathrm{C}$.

\section{Toxicity and mutagenic ability of $A$. camphorata extract}

Before investigating the antimutagenic ability, ACE was used to perform toxicity and mutagenesis tests against $S$. typhimurium TA98, because if the ACE has toxicity and mutagenic effects against S. typhimurium TA98, that would result in revertant numbers and an incorrect judgment regarding their antimutagenic effects. According to previous studies, the maintenance of bacteria number after a sample treatment must reach over $80 \%$ of the colony number of the control to prove the sample has no toxic effect [17]. Results of the toxicity test showed that ACE had no significant effect on S. typhimurium TA98. (Table 2) However, the bacteria count was proportional to the addition of ACE, which could be reasonably explained by the fact that $\mathrm{ACE}$ provides a good nutritional supplement for bacteria growth.

According to the judgment criteria in the method, it would be recognized that the sample possessed mutagenic ability when the number of $\mathrm{His}^{+}$revertants induced by the sample was more than twice the number of spontaneous revertants [18]. The mutagenesis test results indicated that ACE had no effect to cause mutagenesis of S. typhimurium TA98 whether S9 mix was added or not, since the mutagenicity ratio for ACE against S. typhimurium TA98 was between 0.9 and 1.09, indicated that $A$. camphorata extracts induced $\mathrm{His}^{+}$revertants was much less than twice of spontaneous revertants. (Table 3) According to the criteria proposed by Ames et al. in 1975 [18], ACE of experimental concentrations had no toxicity and mutagenic effect. These results were in accordance with the previous study, which

Table 2 Toxicity test for $A$. camphorata extract against $S$. typhimurum TA 98 with $\mathrm{S} 9$

\begin{tabular}{lll}
\hline $\begin{array}{l}\text { Dosage } \\
\text { (mg/plate) }\end{array}$ & \multicolumn{2}{l}{ His $^{+}$revertants (survival, \%) } \\
\cline { 2 - 3 } without S9 & with S9 \\
\hline 0 (control) $^{\mathrm{b}}$ & $1259 \pm 6(100 \%)$ & $1355 \pm 12(100 \%)$ \\
1 & $1245 \pm 10(99 \%)$ & $1338 \pm 10(99 \%)$ \\
0.5 & $1255 \pm 9(100 \%)$ & $1354 \pm 8(100 \%)$ \\
0.25 & $1248 \pm 13(99 \%)$ & $1345 \pm 6(99 \%)$ \\
0.125 & $1260 \pm 12(100 \%)$ & $1363 \pm 7(101 \%)$ \\
0.0625 & $1274 \pm 7(101 \%)$ & $1365 \pm 8(101 \%)$ \\
\hline
\end{tabular}

$100 \mu \mathrm{l}$ S. typhimurium TA98 was mixed with $100 \mu \mathrm{l}$ sample and $500 \mu \mathrm{l}$ phosphate buffer, and incubated at $37^{\circ} \mathrm{C}$ for $20 \mathrm{~min}$, after that the population of $S$. typhimurium TA98 was calculated

${ }^{a}$ Each value is expressed as mean $\pm \operatorname{SD}(n=3)$. Values in parentheses are percentages relative to control value (100\%)

${ }^{b}$ The number of controls was determined without water extracts of A. camphorata
Table 3 Mutagenesis test for $A$. camphorata extract against $S$. typhimurum TA 98 with 59

\begin{tabular}{lll}
\hline Dosage (mg/plate) & \multicolumn{2}{l}{ His $^{+}$revertants (mutagenicity index) } \\
\cline { 2 - 3 } & without S9 & with S9 \\
\hline Spontaneous revertants $^{\mathrm{b}}$ & $165 \pm 10(1.00)$ & $198 \pm 20(1.00)$ \\
1 & $167 \pm 9(1.01)$ & $186 \pm 7(0.93)$ \\
0.5 & $173 \pm 9(1.04)$ & $197 \pm 11(0.99)$ \\
0.25 & $178 \pm 10(1.07)$ & $202 \pm 8(1.02)$ \\
0.125 & $180 \pm 6(1.09)$ & $203 \pm 6(1.02)$ \\
0.0625 & $173 \pm 3(1.04)$ & $204 \pm 12(1.03)$
\end{tabular}

$100 \mu \mathrm{l}$ S. typhimurium TA98 was mixed with $100 \mu \mathrm{l}$ sample and $500 \mu \mathrm{l}$ phosphate buffer, and incubated at $37^{\circ} \mathrm{C}$ for $20 \mathrm{~min}$, after that the population of S. typhimurium TA 98 was calculated

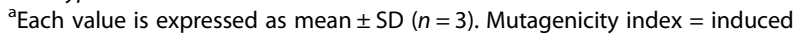
revertants per plate/spontaneous revertants per plate

${ }^{\mathrm{b}}$ The number of spontaneous revertants was determined without water extracts of $A$. camphorata. Values in parentheses are mutagenicity index by using spontaneous revertants as 1

showed that DMSO-extracted ACE had no toxic and mutagenic effect [19].

\section{Antimutagenic ability of $A$. camphorata extract}

Two mutagens can be used to evaluate the ability of $\mathrm{ACE}$ in the antimutagenic test. One is 4-nitro-quinoline$\mathrm{N}$-oxide (4-NQNO), which need not the activation by liver's enzyme system. The other one is Benzo[a]pyrene $(\mathrm{B}[\mathrm{a}] \mathrm{P})$, which requires a liver enzyme to activate its mutagenic ability.

The results of the antimutagenic test showed that ACE has significant effects against 4-NQNO to reduce mutagenesis in different dose treatments with inhibition effects of 7.22, 25.52, 31.82, 36.64, and $44.08 \%$, and also significant effects against $\mathrm{B}[\mathrm{a}] \mathrm{P}$ in different dose treatments with inhibition effects of 1.85, 18.10, 26.16, 27.45, and $30.05 \%$. The given antimutagenic effect was in proportion to the concentration of the sample whether 4NQNO or $\mathrm{B}[\mathrm{a}] \mathrm{P}$ was used as the mutagen generator (Fig. 2). A DMSO-extracted ACE was studied for its mutagenicity in the previous study [19]. Our mutagenic data from water-extracted ACE were consistent with that from DMSO-extracted ACE, which showed no mutagenic effect for A. camphorata; however, waterextracted ACE showed better antimutagenic effects on both mutagens than DMSO-extracted ACE. According to the assignment for the inhibition effect of mutagenesis, an inhibitory efficiency higher than $40 \%$ indicates a strong antimutagenic agent; an inhibitory efficiency between 25 and $40 \%$ indicates a moderate antimutagenic agent; and an inhibitory efficiency of lower than $25 \%$ indicates a weak antimutagenic agent [7]. Therefore, ACE was suggested to be a strong antimutagenic agent against mutagen 4-NQNO and a moderate antimutagenic agent against mutagen $\mathrm{B}[\mathrm{a}] \mathrm{P}$. It is the first report 


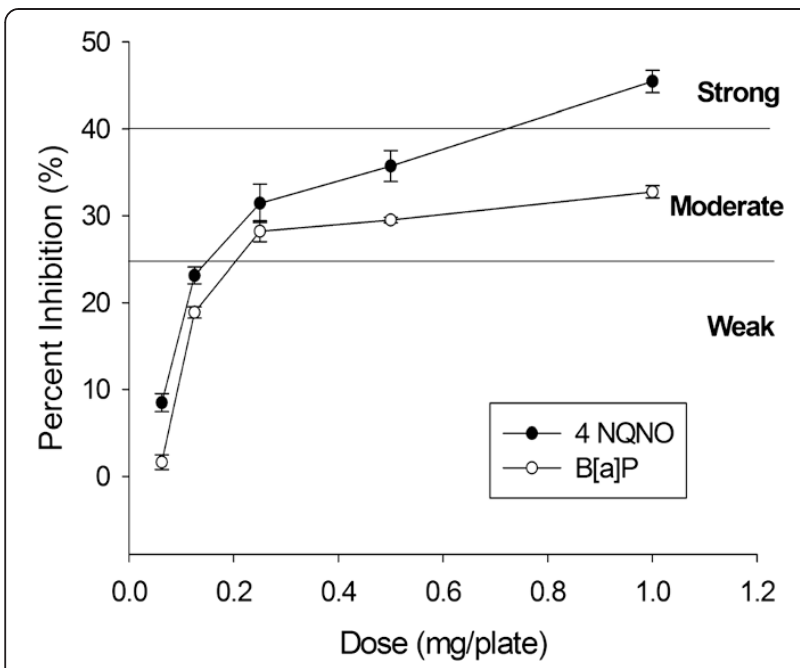

Fig. 2 Results of antimutagenic testing against mutagen 4-NQNO and $\mathrm{B}[\mathrm{a}] \mathrm{P}$ by Anthrodia camphorata extract. Data are expressed as mean \pm $\mathrm{SD}(n=3)$. Inhibition rate $(\%)=\left[1-\right.$ number of $\mathrm{His}^{+}$revertants in the presence of $A$. camphorata extract/number of $\mathrm{His}^{+}$revertants in the absence of $A$. camphorata extract] $\times 100 \%$

to address water-extracted ACE to be a strong or moderate antimutagenic agent against both mutagens.

\section{A. camphorata extract decreases the DNA damage induced by hydroxyl radicals}

Oxidative damage to DNA is one of the most important mechanisms in the initiation of cancer. Such damage is usually caused by hydroxyl radicals [20]. The activity of these radicals can be reduced by natural antioxidants found in plants including many herbs [21]. The Fenton reaction involves the reaction between hydrogen peroxide and $\mathrm{Fe}^{2+}$ to form hydroxyl radicals. Scavengers of hydroxyl radicals inhibit this reaction through the reduction of $\mathrm{Fe}^{2+}$ $[8,9]$. It was found that ACE at a concentration of $0.8 \mathrm{mg} /$ $\mathrm{ml}$ was able to reduce the hydroxyl radical-induced damage in calf thymus DNA by approximately $82.8 \%$ (Fig. 3). Since ACE possesses good antioxidant activity,

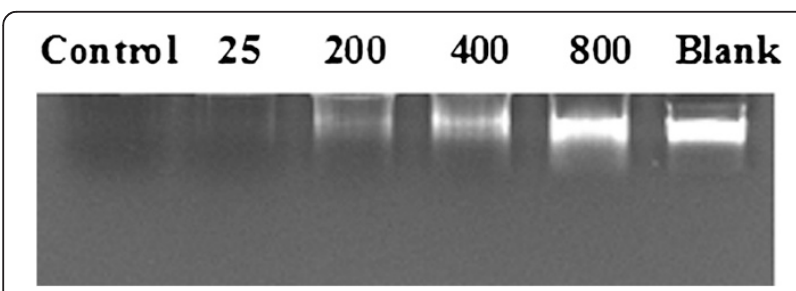

Fig. 3 Results of a calf thymus DNA protection test against hydroxyl radical-induced damage by Anthrodia camphorata extract. Samples were a blend of $A$. camphorata extract ( $\mu \mathrm{g}$ total solids $/ \mathrm{ml}$ ), calf thymus DNA solution, $\mathrm{FeSO}_{4}$, and hydrogen peroxide; Blank was calf thymus DNA solution; Control was the reaction mixture containing no $A$. camphorata extract its protective effects on DNA should have contribution from its antioxidant activity.

\section{Conclusions}

A. camphorata extract (ACE) was found to be a good antioxidant by its good scavenging ability against DPPH radicals. ACE showed no toxicity and mutagenic effect in the toxicity and mutagenic ability studies; moreover, it demonstrated good anti-mutagenic ability against both direct mutagen 4-NQNO and indirect mutagen $\mathrm{B}[\mathrm{a}] \mathrm{P}$. ACE showed the DNA-protective activity by its good ability in reducing hydroxyl radical-induced DNA damage. These results suggested that $A$. camphorata is a new and novel material for health foods with antioxidant, antimutagenic and DNA-protective activities.

\section{Abbreviations}

ACE: Antrodia camphorata extract; DPPH: 2,2-diphenyl-1-picrylhydrozyl; 4NQNO: 4-nitroquinoline N-oxide; B[a]P: benzo[a]pyrene; BHT: butylated hydroxytoluene; DMSO: dimethyl sulfoxide.

\section{Competing interests}

The authors declare that they have no competing interests.

\section{Authors' contributions}

YLH carried out experiments and data analyses in this study. SPW was involved in the coordination of the experiments and the writing of manuscript. LWF assisted to carry out all experiments and penned the manuscript. TSH was involved in the experimental design, coordination of the experiment and revision of the manuscript. All authors read and approved the final manuscript.

\section{Acknowledgments}

This study was supported by the basic research funding from I-Shou University and a grant from Chinese Culture University (Industry-Academy Project CCU2011-Oryan-01). We thank Prof. Szu-Chuan Shen (National Taiwan Normal University) for his suggestion on experiments and critical review on manuscript.

\section{Author details}

${ }^{1}$ Department of Nutrition, I-Shou University, No. 8, Yida Rd., Jiaosu Village, Yanchao District, Kaohsiung City, Taiwan. ${ }^{2}$ Department of Biotechnology and Pharmaceutical Technology, Yuanpei University, No. 306, Yuanpei St, Hsinchu City, Taiwan. ${ }^{3}$ Graduate Institute of Biotechnology, Chinese Culture University, No. 55, Hwa-Kan Rd, Yang-Ming-Shan, Taipei, Taiwan.

Received: 26 January 2015 Accepted: 7 July 2015

Published online: 16 July 2015

\section{References}

1. Wu S-H, Ryvarden L, Chang T-T. Antrodia camphorata ("niu-chang-chih"), new combination of a medicinal fungus in Taiwan. Bot Bull Acad Sin. 1997;38:273-5

2. Geethangili M, Tzeng YM. Review of pharmacological effects of Antrodia camphorata and its bioactive compounds. Evid Based Complementary Altern Med. 2009;2011:1-17.

3. Crisan EV, Sands A. Nutritional value. In: Chang ST, Hayes WA, editors. The biology and cultivation of edible mushrooms. New York: Academic; 1978. p. 137-65.

4. Taga MS, Miller EE, Pratt DE. Chia seeds as a source of natural lipid antioxidants. J Am Oil Chem Soc. 1984;61:928-31.

5. Lee $\mathrm{CH}$, Yang L, Xu JZ, Yeung SY, Huang Y, Chen ZY. Relative antioxidant activity of soybean isoflavones and their glycosides. Food Chem. 2005;90:735-41.

6. Maron DM, Ames BN. Revised methods for the salmonella mutagenicity test. Mutat Res. 1983;113:173-215. 
7. Ikken Y, Morales P, Martinez A, Marin ML, Haza Al, Cambero Ml. Antimutagenic effect of fruit and vegetable ethanolic extracts against $\mathrm{N}$-nitrosamines evaluated by the Ames test. J Agric Food Chem. 1999;47:3257-64.

8. Dreher D, Junod AF. Role of oxygen free radicals in cancer development. Eur J Cancer. 1996:32:30-8.

9. Halliwell B, Gutteridge JMC, Aruoma OI. The deoxyribose method: simple "test-tube" assay for determination of rate constants for reactions of hydroxyl radicals. Anal Biochem. 1987;165:215-9.

10. Hsu WC. Analysis of chemical components and biological activity of polysaccharides from mycelia of Antrodia cinnamomea. Master Thesis, Department of Agronomy, National Taiwan University, Taipei, Taiwan. 2005.

11. Aparicio-Ferandez X, Manzo-Bonilla L, Lorarca Piña G. Comparison of antimutagenic activity of phenolic compounds in newly harvested and stored common beans Phaseolus vulgaris against Aflatoxin B1. J Food Sci. 2005;70(S):73-S78.

12. Mejia EG, Castano-Tostado E, Loarca-Pina G. Antimutagenic effects of natural phenolic compounds in beans. Mut Res. 1999:441:1-9.

13. Shimada K, Fujikawa K, Yahara K, Nakamura T. Antioxidative properties of xanthan on the autoxidation of soybean oil in cycodextrin emulsion. J Agic Food Chem. 1992;40:945-8.

14. Song TY, Yen G-C. Antioxidant properties of Antrodia camphorata in submerged culture. J Agric Food Chem. 2002;50:3322-7.

15. Mau J-L, Huang P-N, Huang S-J, Chen C-C. Antioxidant properties of methanolic extracts from two kinds of Antrodia camphorata mycelia. Food Chem. 2004;86:25-31.

16. Huang S-J, Mau J-L. Antioxidant properties of methanolic extracts from Antrodia camphorata with various doses of $y$-irradiation. Food Chem. 2007;105:1702-10.

17. Waleh NS, Rapport SJ, Mortelmans KE. Development of a toxicity test to be coupled to the Ames Salmonella assay and the method of construction of the required strains. Mut Res. 1982;97:247-56.

18. Ames BN, McCann J, Yamasaki E. Methods for detecting carcinogens and mutagens with the Salmonella / mammalaian-microsome mutagenicity test. Mut Res. 1975;31:347-64.

19. Wu M-F, Peng F-C, Chen Y-L, Lee C-S, Yang Y-Y, Yeh M-Y, et al. Evaluation of genotoxicity of Antrodia cinnamomea in the Ames test and the in vitro chromosomal aberration test. In Vitro. 2011;25:419-24.

20. Athukorala Y, Kim KN, Jeon YJ. Antiproliferative and antioxidant properties of an enzymatic hydrolysate from brown alga, Ecklonia cava. Food Chem Toxicol. 2006;44:1065-74.

21. Reddy L, Odhav B, Bhoola KD. Natural products for cancer prevention: a global perspective. Pharmacol Ther. 2003;99:1-13.

\section{Submit your next manuscript to BioMed Central and take full advantage of:}

- Convenient online submission

- Thorough peer review

- No space constraints or color figure charges

- Immediate publication on acceptance

- Inclusion in PubMed, CAS, Scopus and Google Scholar

- Research which is freely available for redistribution 